\title{
DROGAS SINTÉTICAS NA LEGISLAÇÃO BRASILEIRA
}

\author{
Nyeda Yuri Santos Kiyota Dan, Airton Roberto Guelfi \\ Universidade do Oeste Paulista - UNOESTE, curso de Direito, Presidente Prudente, SP. E-mail: \\ nyedakiyota@hotmail.com; del.guelfi@gmail.com
}

\section{RESUMO}

Apresenta-se o devido trabalho visando um estudo e uma análise jurídica do crime de tráfico de entorpecentes (Lei $n$ ㅇ 11.343/06) esclarecendo sua estrutura, com ênfase na atuação da ANVISA (Portaria SVS/MS 344/98), as substâncias tidas como sintéticas, a classificação de drogas psicotrópicas, estabelecendo uma correlação entre as catalogadas e não no rol regulamentador e conceituação de termos essenciais para compreensão da referida Lei. Será abordada a hipótese de tipificação, atendo-se ao objeto material do crime e as alterações no sistema nervoso central por ele provocado, bem como uma reflexão quanto à relevância saúde e segurança pública. Por fim, demonstrar-se-á que a criminalização unicamente das que se encontram listadas não é satisfatório a efetividade da norma jurídica, carecendo de ajustamento equiparativo, por conseguinte atualizações constantes para preenchimento da norma penal em branco das consideradas de uso proscrito.

Palavras-chave: drogas, sintéticas, ANVISA, tipificação, efeitos.

\section{SYNTHETIC DRUGS IN BRAZILIAN LEGISLATION}

\section{ABSTRACT}

The adequate work is presented for a study and legal analysis of the crime of drug trafficking (Law $\mathrm{n}$ o 11.343 / 06), clarifying its structure, with emphasis on the work of ANVISA (Portaria SVS / MS 344/98), the substances considered as Synthetic, the classification of psychotropic drugs, establishing a correlation between those cataloged and not in the regulatory role and conceptualization of essential terms for understanding the said Law. The hypothesis of typification will be approached, taking into account the material object of the crime and the changes in the system Central nervousness caused by it, as well as a reflection on the relevance of health and public safety. Finally, it will be demonstrated that the criminalization of only those that are listed is not satisfactory the effectiveness of the legal norm, needing a matching adjustment, consequently constant updates to fill the blank penal norm of those considered forbidden use.

Keywords: Drugs, synthetic, ANVISA, typing, effects.

\section{INTRODUÇÃO}

Considerando o crime de tráfico de entorpecente um problema de proporções a nível global, existente em todas as classes sociais, de crescimento desmesurado, tendo como público alvo os jovens, causador de um quadro clínico que não se vislumbra a cura e sim de tratamento ininterrupto, combate-lo é garantia de incolumidade a sociedade.

O crescimento do número de usuários é estarrecedor e quando observados os efeitos físicos e psíquicos o panorama se torna mais catastrófico, já que a propensão é o aumento do consumo e/ou a substituição por drogas "mais pesadas", ocasionando portadores de toxicomania.

O agravamento advém de elementos heterogêneos, na ocasião em que são distribuídos em ordem, percebe-se que um constitui resultado do precedente que é condição necessária do posterior, formando uma cadeia solidificada pelo crime organizado. É nesse cenário que o 
ordenamento jurídico deve acompanhar o aperfeiçoamento das substâncias sintéticas, por diretrizes consoantes a contemporaneidade, em virtude do impacto nocivo e implacável.

\section{METODOLOGIA}

É um estudo voltado a explorar a realidade de um crime em virtude da evolução científica e globalização. A metodologia a ser aplicada diz respeito ao método hipotético-dedutivo, usando de forma auxiliar o comparativo, tendo em conta tratar-se de crime regulado por norma penal em branco e adequação na aplicação do direito. Desenvolvido por intermédio de pesquisas bibliográficas, doutrinas, jurisprudências e artigos. Versando a possibilidade de elucidação das muitas síncopes sociais, alargando as perspectivas e o aperfeiçoamento das ciências jurídicas.

\section{DISCUSSÃO}

A palavra droga tem origem no termo holandês droog, que se define como folha seca, isso em razão dos produtos naturais serem a base para maior parte dos fármacos na medicina remota. (DENARC)

O artigo 4으, I, da Lei № 5.991 de 17 de dezembro de 1973, trata como droga qualquer substancia ou matéria-prima que tenha finalidade medicamentosa ou sanitária. Desta rotulagem, segmentam-se em lícitas e ilícitas. O primeiro grupo compreende aquelas cuja compra e venda são autorizadas por lei, tanto para uso recreativo, como tabaco e bebidas com teor alcoólico, como para uso terapêutico prescrito por profissional médico. As ilícitas, são as substancias psicotrópicas, com comercialização vedada pela legislação, configurando como crime a violação aos dispositivos.

Em consonância com a Organização Mundial da Saúde, droga é qualquer substância apta a ocasionar alterações no funcionamento do organismo. Em complementação a tal conceito, cabe ensinamento de ANDREUCCI (2016, p. 216), ao esclarecer que para que assim sejam consideradas, é imprescindível que possuam "potencial de causar dependência, com condição de que estejam relacionadas em dispositivo legal competente". A legislação brasileira por sua vez, trouxe a definição no artigo 1ำ, parágrafo único da Lei no 11.343/2006, sendo o objeto material do crime, substancias ou produtos capazes de causar dependência, assim especificados em lei ou relacionados em listas atualizadas periodicamente pelo Poder Executivo da União.

Refere-se, por conseguinte, as drogas elencadas na Portaria SVS/MS n0344/98, referem-se às psicotrópicas. Essa designação foi estabelecida pela Organização Mundial da Saúde em 1981, e se caracteriza como as que agem no sistema nervoso central, produzindo alterações de comportamento, humor e cognição, possuindo grande propriedade reforçadora, sendo passível de autoadministração. Em síntese, são as de uso não aprovada pela medicina, haja vista não apresentarem capacidade terapêutica das drogas em sua modalidade medicamentosa, somente fomentam em dependência, levando a toxicomania.

A OMS adotou dependência como sendo "quando a pessoa não consegue largar a droga, porque o organismo se acostumou com a substância e sua ausência provoca sintomas físicos (quadro conhecido como Síndrome da Abstinência), e/ou porque se acostumou a viver sob os efeitos da droga, sentindo grande impulso de usá-la com frequência". Nessa esteira, a concepção de Benfica (2008, p. 118 e 119) faz-se pertinente:

Dependência: Na falta da droga, os usuários que se acostumaram a consumi-la apresentam sintomas penosos, levando a um desejo e a uma necessidade absoluta de consumo. Este quadro caracteriza a chamada "dependência física", um estado de adaptação do corpo, manifestado por distúrbios físicos quando o uso de uma droga é interrompido. Quando uma determinada droga é utilizada em quantidades frequências elevadas, o organismo se defende estabelecendo um novo equilíbrio em seu 
funcionamento e adaptando-se a esta substancias de tal forma que, na sua falta, funcionou mal. Na dependência física, a droga é necessária para que o corpo funcione normalmente. Assim, a suspensão do uso desta substância manifesta-se através de um desajuste metabólico no organismo, normalmente caracterizado por sensações de mal-estar e diferentes graus de sofrimento mental e físico, particulares para cada tipo de droga. Este quadro é chamado de "Síndrome de Abstinência" e representa o conjunto de sinais e sintomas decorrentes da falta da droga em usuários dependentes.

Sendo assim, compreende-se que a dependência é o ápice da toxicomania, na conceituação da OMS, se traduz em "estado de intoxicação crônica ou periódica, prejudicial ao individuo e nociva à sociedade, pelo consumo repetido de determinada droga, seja ela natural ou sintética".

É nesse cenário que a supracitada lei, ao dispor as medidas de prevenção ao uso, reinserção de usuários dependentes, normas de repressão à produção não autorizada e tráfico ilícito, bem como, definir os crimes, suas penas, procedimentos processuais e diversas outras diretrizes, demostra sua magnitude, quando observada da perspectiva social, que engloba tanto a segurança pública em virtude do tráfico organizado, como da saúde, ao se tratar de quadro clínico que só pode ser sanado mediante tratamento contínuo.

As drogas podem ser catalogadas, com base nos mais diversos padrões, abordaremos quanto à origem e conforme as modificações provocadas na atividade mental.

2.1 - Quanto á origem:

a) Drogas naturais: são as extraídas da natureza, sem intervenção de processo químico em sua composição, como ópio, maconha e DMT.

b) Drogas sintéticas: são as criadas usando sustâncias químicas artificiais ao invés de ingredientes naturais, á exemplo LSD, ecstasy e metanfetaminas.

c) Drogas semissintéticas: tem como base drogas naturais, com alterações químicas geradas em laboratório, exemplificando crack, heroína e cocaína.

2.2 - Quanto aos efeitos nos sistema nervoso central:

Este é agrupamento mais acolhido, foi elaborado pelo pesquisador francês Louis Chaloult, leva em conta as reações comportamentais e fisiológicas no indivíduo ao ingeri-las, inalá-las ou injetá-las.

a) Drogas depressoras: fazem com que o cérebro funcione morosamente, reduzindo a atividade motora, provocam assim mudança quantitativa; são conhecidas como psicolépticos, ocasionam sonolência, lentidão, apatia, perda da memória, falta de coordenação motora entre outros. Tem-se nesta categoria os barbitúricos, benzodiazepínicos, opiáceos e outros. (ZANELATTO; LARANJEIRA, 2013, p.46)

b) Drogas estimulantes: são capazes de aumentar a atividade cerebral, ocasionam variação quantitativa; são reputadas como psicoanalépticos, os usuários sob seus efeitos permanecem em estado de alerta desmedido, eufóricos, com perda do apetite e sono. Englobam as anfetaminas, crack e cocaína.

c) Drogas perturbadoras: antagônico aos grupos acima expostos, a alteração é qualitativa, gera mudanças no funcionamento cerebral levando o usuário a quadros de delírios e alucinações; são denominados alucinógenos. São exemplos o ecstasy, LSD-25, maconha e o cogumelo do gênero psilocybe.

Nessa esteira faz-se importante explanação de Sérgio Niscatri (2014, p.95): 
podemos definir alucinação como uma percepção sem objeto, ou seja, a pessoa vê, ouve ou sente algo que realmente não existe. Delírio por sua vez, pode ser definido como um falso juízo da realidade, ou seja, o indivíduo passa a atribuir significados anormais aos eventos que ocorrem em sua volta. Esse tipo de fenômeno ocorre de modo espontâneo em certas doenças mentais, denominadas psicoses, razão pela qual as drogas também são chamadas de psicomiméticos.

Como já citado, as drogas sintéticas são provenientes de substâncias artificiais, ou seja, a estrutura molecular não conserva elementos extraídos da natureza, e são popularmente conhecidas como "designer drug". Na interpretação de LARANJEIRA E ZANELATTO (2013, p.65):

têm como característica principal o fato de terem sido modificadas em laboratório, como intuito de potencializar ou criar efeitos psicoativos e evitar efeitos indesejáveis. A disponibilidade e o barateamento tecnológico permitem, hoje, que tais substâncias sejam sintetizadas em laboratórios clandestinos domésticos.

A Fundação Internacional Para Um Mundo Sem Drogas, pioneira na batalha contra esse tipo de entorpecente esclarece o intuito daqueles que as colocam no mercado do tráfico, que é apenas um, burlar a lei. A estratégia é empregar assíduas mutações naquelas que já foram classificadas como ilícitas, gerando uma "original" e possam comercializar sem infringir os ditames legais. A complicação, uma das muitas, reside no fato dos usuários não anteverem os resultados no organismo, alguns capazes de provocar a morte. A entidade relata dados estáticos alarmantes, ao apontar que entre 2009 e 2014 foram detectadas aproximadamente 300 "designer drugs".

A ANVISA é a Agência Nacional de Vigilância Sanitária, criada através da Lei no 9.728 de 26 de janeiro de 1999, vinculada ao Ministério da Saúde, tendo por finalidade institucional promover a proteção da saúde da população, mediante a intervenção nos riscos decorrentes da produção e do uso de produtos e serviços sujeitos a vigilância sanitária.

Nesse contexto a atuação da agência abarca a regulamentação e controle de substâncias capazes de causar dependência química, seja lícita ou ilícita, por meio da Portaria SVS/MS 344/98, conforme disposição do artigo $8^{\circ}, \S 10$, I, da referida lei, que sujeita medicamentos os de uso humano, suas sustâncias ativas e demais insumos, processos e tecnologias a fiscalização sanitária.

O caput do artigo 33 da Lei de Drogas tipifica a conduta criminalizadora de tráfico, representada por dezoito verbos, tratando-se de tipo penal misto alternativo. Todavia, não elenca a materialidade delitiva de forma pormenorizada, se restringe a mera menção do vocábulo drogas, versando assim norma penal em branco que reclama complementação de outra norma conforme entendimento de Damásio (2008, p. 110) "a exequibilidade da norma penal em branco depende, pois, de complementação de outras normas jurídicas ou futura expedição de certos atos administrativos".

$\mathrm{Na}$ atualidade a listagem dos psicotrópicos e entorpecentes acha-se na aludida portaria, cuja modificação para inserção ou exclusão de substâncias é feitas sob forma de resolução, cuidase assim, de rol taxativo que supri a base para preenchimento da norma penal em branco.

Tendo em vista a estrutura da catalogação da portaria, as substâncias de uso proscrito no Brasil encontram-se nas listas: Lista E- lista de plantas proscritas que podem originar substâncias entorpecentes e/ou psicotrópicas; Lista F - lista das substâncias de uso proscrito no Brasil; Lista F1 - substâncias entorpecentes; Lista F2 - substâncias psicotrópicas; Lista F3 - substâncias precursoras e Lista F4 - outras substâncias. 
O elemento normativo do crime de tráfico acha-se na expressão "sem autorização ou em desacordo com determinação legal ou regulamentar", destarte, a inexistência do entorpecente na lista da ANVISA torna a conduta do agente atípica. Entretanto o artigo 33,§1으, I, traz figuras equiparativas aquele que incorre em qualquer dos atos executórios elencados que tem como objeto material matéria-prima, insumo ou produto químico destinado à preparação de drogas. Segundo ensinamento de Vicente Greco $(1987$, p. 97) matéria-prima é:

substância de que podem ser extraídos ou produzidos os entorpecentes ou drogas que causem dependência física ou psíquica. Não há necessidade de que as matérias-primas tenham já de per si os efeitos farmacológicos dos tóxicos a serem produzidos: basta que tenham as condições e qualidades químicas necessárias para, mediante transformação, adição etc., resultarem em entorpecentes ou drogas análogas.

Em consequência do dispositivo é concebível sustentar, que ainda que a droga não esteja classificada no rol regulamentador, o fato de ostentar substância de uso proscrito em sua estrutura como um todo, tendo como propósito a prática criminosa, é apto ao enquadramento do tipo penal, ao preencher os requisitos de autoria e materialidade. Consoante à lição de MORAES (2008, p. 110) "para complementação da norma penal em branco, não se faz necessário que a obrigatória listagem contenha o nome comercial do remédio o substância química, mas que esteja presente em sua composição alguma substância entorpecente".

Na contemporaneidade, ater-se literalmente a listagem suplementar não é hábil suficiente para aplicação dos preceitos legais, a julgar pela alta tecnologia empregada pelos laboratórios visando abastecer um comércio cada vez mais lucrativo, que acarreta crime organizado; roubo de carga; violência, sobretudo em comunidades carentes; envolvimento de menores a criminalidades entre outros males impulsionadores do colapso social.

Portanto tendo em conta a alteração da atividade cerebral, que configura desvios de comportamento, é satisfatório para o preenchimentos dos requisitos do ilícito penal, que as drogas sintéticas "adulteradas" não constantes no rol, serem tidas como objeto material do crime. Do contrário o emprego da atipicidade pela falta de elementos legais leva a impunidade, em decorrência de insuficiência probatória. Nessa perspectiva, a posição da jurisprudencial:

APELAÇÃO CRIMINAL - TRÁFICO DE ENTORPECENTES - SENTENÇA ABSOLUTÓRIA POR INSUFICÊNCIA DE PROVAS PARA CONDENAÇÃO (CPP, ART. 386, VII) - IRRESIGNAÇÃO DEFENSIVA - PRETENDIDA ABSOLVIÇÃO COM FUNDAMENTO NO INCISO III OU IV DO ART. 386 DO CPP IMPERTINÊNCIA - PROVA ORAL APTA A REVELAR A AUTORIA DELITIVA ACUSADO SURPREENDIDO NA POSSE DE SUBSTÂNCIA APARENTEMENTE PROSCRITA - CONFISSÃO EXTRAJUDICIAL - EXAME TOXICOLÓGICO INCONCLUSIVO QUANTO ÀS PROPRIEDADES DA SUBSTÂNCIA APREENDIDA, NÃO SENDO POSSÍVEL AFERIR A SUA NATUREZA - POSSIBILIDADE DE TRATAR-SE DE "DROGA SINTÉTICA", CUJA ESTRUTURA MOLECULAR É ALTERADA POR MANIPULADORES PARA BURLAR ÓRGÃOS DE FISCALIZAÇÃO - MATERIALIDADE DELITIVA QUE RESSAI DUVIDOSA ARCABOUÇO FÁTICO-PROBATÓRIO INSUFICIENTE PARA EMBASAR A CONDENAÇÃO - INCIDÊNCIA DO BROCARDO IN DUBIO PRO REO PROVIMENTO JURISDICIONAL ESCORREITO, NÃO MERECENDO REPAROS RECURSO DESPROVIDO. Malgrado a existência de prova oral capaz de atestar a autoria delitiva do acusado, remanescendo dúvida quanto à materialidade, na medida em que o exame toxicológico mostrou-se 
inconclusivo quanto à natureza da substância apreendida, impõe-se a manutenção de sua absolvição, com supedâneo no inciso VII, do art. 386 do CPP, ante a insuficiência de provas para embasar a condenação.

Neste seguimento, o Decreto no 79.388 de 14 de março de 1977 promulga a Convenção de Viena sobre drogas psicotrópicas datada de 1971, preconiza em seu artigo 2ㅇ, §4ㅇ que a substância seja apta a ocasionar: estado de dependência; estímulo ou depressão do sistema nervoso central, provocando alucinações ou perturbações das funções motoras, ou do raciocínio, ou do comportamento, o da percepção ou do estado de ânimo; abusos e efeito nocivo semelhantes aos de uma substância constante das Listas I, II, III ou IV.

\section{CONCLUSÃO}

Com base no estudo desenvolvido nesta pesquisa, é concebível reconhecer que malgrado as atualizações da lista de entorpecentes de uso proscrito, a legislação depara contratempos em vista da evolução científica. Na contemporaneidade, ater-se literalmente a listagem suplementar não é hábil o suficiente para aplicação dos preceitos legais, a julgar pela alta tecnologia empregada pelos laboratórios visando abastecer um comércio cada vez mais lucrativo, que acarreta crime organizado; roubo de carga; violência, sobretudo em comunidades carentes; envolvimento de menores a criminalidades entre outros males impulsionadores do colapso social.

Vários foram e são os feitos em que a justiça brasileira em vista da inexistência de materialidade delitiva, foi compelida a lançar mão do brocardo in dubio pro reu, prolatando sentenças absolutórias quando notoriamente a substância portada pelo agente era correlata as identificas e propícia a causar os efeitos destas.

É entendível que acompanhar a ciência high-tech é laborioso, contudo, é crucial uma elucidação coerente e franqueável, dado que o bem jurídico tutelado pela norma regulamentadora do tráfico destina-se ao bem-estar da coletividade.

\section{REFERÊNCIAS}

ANDREUCCl, Ricardo Antonio. Legislação Penal Especial. 11 ed. São Paulo: Saraiva, 2016, p. 216.

Agência Nacional de Vigilância Sanitária. Institucional. Disponível em: < <http://portal.anvisa.gov.br/instituciona>l. Acesso em: 05 maio. 2017.

BENFICA, Francisco Silveira. Medicina Legal. Porto Alegre: Livraria do Advogado Editora, 2008, p.118-119.

BRASIL. Congresso Nacional. Lei no. 5.991, de 17 de dezembro de 1973. Dispõe sobre o controle sanitário do comercio de drogas, medicamentos, insumos farmacêuticos e correlatos e dá outras providências. Diário Oficial da União, Brasília, DF, 17 dez. 1973. Disponível em: <http://www.planalto.gov.br/ccivil_03/leis/L5991.htm>. Acesso em: 04 ago. 2017

BRASIL. Congresso Nacional. Lei no. 9.782, de 26 de janeiro de 1999. Define o sistema nacional de vigilância sanitária, e dá outras providências. Diário oficial da União. Brasília, DF, 26 jan. 1999. Disponível em: <http://www.planalto.gov.br/ccivil_03/leis/L9782.htm>. Acesso em: 04 ago. 2017.

BRASIL. Decreto n.o 79.388, de 14 de março de 1977. Promulga a Convenção sobre as Substâncias Psicotrópicas. Diário oficial da União. Brasília, DF, 14 Mar. 1977 
<http://www2.camara.leg.br/legin/fed/decret/1970-1979/decreto-79388-14-marco-1977-

428455-publicacaooriginal-1-pe.html>. Acesso em: 04 ago. 2017.

BRASIL. Congresso Nacional. Lei no. 11.343, de 23 de agosto de 2006. Institui o Sistema Nacional de Políticas públicas sobre drogas- Sisnad; prescreve medidas para prevenção do uso indevido, atenção, reinserção social de usuários dependentes de drogas; estabelece normas para repressão à produção não autorizada e ao tráfico ilícito de drogas; define crimes e dá outras providências. Diário Oficial da União, Brasília, DF, 23 de Ago. 2006. Disponível em:

< http://www.planalto.gov.br/ccivil_03/_ato2004-2006/2006/lei/l11343.htm>. Acesso em: 04 de ago. 2017.

Foundation for a Drug-Free World. "DESIGER DRUGS" - UMA EXPERIÊNCIA ARRISCADA, 2016. Disponível em: < http://www.mundosemdrogas.org.br/drugfacts/synthetic.html>. Acesso em: 28 jul. 2017.

GRECO, Vicente Filho. Tóxicos: prevenção-repressão: comentários à Lei n. 6.3668, 21-10-1976. 5 ed. São Paulo: Saraiva, 1987, p. 97.

Instituto de Medicina Social e Criminologia de São Paulo. Psicotrópicos. Disponível em: <http://www.imesc.sp.gov.br/infodrogas/Psicotro.htm>. Acesso em: 07 maio. 2017.

JESUS, Damásio Evangelista de. Código Penal Anotado. 18 ed. São Paulo: Saraiva, 2008, p. 110.

LARANJEIRA, Ronaldo; ZANELATTO, Neide. 1 ed. O Tratamento da Dependência Química e as Terapias Cognitivo-Comportamentais. Porto Alegre: ArtMed, 2013, p. 65.

MORAES, Alexandre de; SMANIO, Gaianpaolo Poggio. Legislação Penal Especial. 10 ed. São Paulo: Atlas, 2008, p. 110.

PENTEAdO, Nestor Sampaio Filho. Col. Preparatória Para Concurso de Delegado de Polícia Criminologia e Medicina Legal. 1 ed. São Paulo: Saraiva, 2014.

NISCATRI, Sérgio. Curso de Prevenção do Uso de Drogas para Educadores de Escolas Públicas. 6 ed. Brasília, 2014, p. 88-89. 